\title{
The time of money in finance and US society
}

\author{
Elena Esposito \\ University of Bielefeld, Germany/University of Modena-Reggio Emilia, Italy
}

\begin{abstract}
Traditional societies were defined by a prevalence of the past in the definition of the present. United States (US) society seems to show the opposite trend: the present is defined as the preparation of the future. Financial temporality can be seen as an example of the present use of the future, transforming future possibilities into available wealth. As the financial crisis has shown, however, the temporality of the future is more complex and circular. This article deals with quantitative easing (QE) as a financial instrument with an essentially temporal nature (in the sense that it uses time and acts on the future and on expectations). The success of QE in the US economy reveals essential aspects of US temporality, but also raises questions as to how it may differ from European temporality. The analysis of QE measures and their impact also offers ways to assess whether and by which means politics can intervene into finance, as well as what consequences and uncertainties are created in the process.
\end{abstract}

\section{Keywords}

Structured finance, risk, futurity, quantitative easing, performativity, money

\section{Introduction: Temporalities of finance}

The contributions in this special issue deal with finance and temporality, and more specifically with the role and importance of time, as a constraint and as an opportunity, for finance. This raises many questions and allows us to deal indirectly with other key issues such as the relationship between finance and the economy, or even the social role of time in general. Because without taking into account the dimension of time, one cannot explain the meaning and function that money has had at the base of our monetarized economy for several centuries, nor the relevance and the spread of finance. Yet, the issue's aims and scope are more focused and more ambitious, addressing not only the temporality of the economy in general, but also economic temporalities in the plural, in US culture, and through comparative

\section{Corresponding author:}

Elena Esposito, Fakultät für Soziologie, Universität Bielefeld, Universitätsstraße 25, 33615 Bielefeld, Germany. Email: elena.esposito@unimore.it 
and interdisciplinary approaches. This allows us to put our questions into a broader and more precise perspective. It also gives us an empirical reference, which for sociologists is always a big advantage. Does financial temporality allow us to study the specific way a culture sets and uses the reference to time as a social category? Can it help to understand the similarities and differences (if any) between US and European temporalities, in an area (finance) that has made globalization one of its most evident (and most criticized) features?

I will deal with a specific example, concerning the introduction of a financial instrument in Europe that has an essentially temporal nature (in the sense that it uses time and acts on the future and on expectations) - namely, the monetary policy of quantitative easing (QE), which has previously been successfully applied in the US economy. This success tells us something about essential aspects of US temporality, but it also raises questions as to how it may be different from European temporality, and therefore, it gives cause to worry about the effectiveness of QE measures in a European context. It is therefore a useful study case for comparing economic temporalities in the US and in Europe. The analysis of QE measures and their impact also offers ways to assess whether and by which means politics can intervene into finance, as well as what consequences and uncertainties are created in the process.

\section{The unknowable future as a resource}

Economic temporalities concern the relationship between money and time, or the temporal nature of money. Marx already recognized that money has a crucial temporal component, and is based primarily on the use and exploitation of temporal advantages. ${ }^{1}$ It was Keynes, however, and after him Shackle and several others, who showed that the reference to time is the basis of the function and usefulness of money. As economists have long told us, money allows one to evaluate goods and to exchange them, but it can only do so because it implies a reference to time. Money puts the individual goods into relation with future goods and needs, and allows them to be managed.

Money is abstract, which means that it is independent from the characteristics of each specific good (Sohn-Rethel, 1990). Price is a number, and it does not indicate if you are buying a book or a weapon or a sandwich. A sum of money does not refer to any specific good because it generally refers to all possible goods and relates them with one another. One can use it to buy a given commodity, but for everything that one buys, one does not buy something else. Each purchase is compared with all alternative purchases, with all the other things one could buy in its place.

Why is this an advantage, and how does it work? As long as we refer only to the present moment, the advantage is limited, and in fact barter may suffice (provided that one has a means to compare different goods). Money allows such comparisons because of its correlated functions of measure of value and medium of exchange, which have always been observed by economists (on this see Ingham, 2004). In every present moment, the available (present) goods as well as the needs to be met are limited, and the goal of exchange is simply to coordinate the needs of everyone. However, we do not refer only to the present, and as soon as we include further time references in our perspective, and in particular if we include the future, the situation becomes more complex. Everyone knows that there are other goods one might enjoy, if one has time to get them, and everyone knows that in the future one will have other needs, some of which one can already imagine and many others one does not yet anticipate. With regard to the future, needs become unlimited because the future is open and unknown, and does not allow one to know in the present what one might need or when. We do 
not yet know what the future will bring and what we might need, but we can already be afraid of not being able to get it and worry about it.

At this point, money's temporal function as the "link between the present and the future" comes into play (Keynes, 1936: 293), and here its abstraction becomes a critical advantage. Since a sum of money does not give any indication about the goods that one can acquire (and imposes no limit other than its size), its purchasing power can refer freely to the indeterminate mass of all possible future goods, in response to the undetermined needs that may arise. I do not know what I might need, but I know that if I have money I will be able to get it. And since the future is unknown, all possible needs are undetermined as well. Money, which one can spend as one sees fit (even in ways that one does not yet know), represents - in the abstract all possible needs. We need money now because we do not know what we may need in the future, and we are, therefore, always in need, not of goods, but of money. Rather than to satisfy our needs, the monetary economy seems to generate the needs upon which it operates. Without money, there would not be the needs that money serves to satisfy. Consequently, money is never enough.

Moreover, money (in its liquid form) does not have an expiration date, nor is it bound to a specific moment. Because it is abstract and indeterminate, its value remains, even if one waits before spending it. It remains available even when one defers the decision in view of other situations, other partners, or different conditions. The meaning and function of money lies in this temporal delay, in the possibility that money offers to use time in order to increase our opportunities for decision and our options of choice; one can use time to gather information about the world and about one's needs. In this sense, money operates as a "medium of deferment and of search" (Shackle, 1972: 160; see also 1990: 213), offering the time it takes to deal with the unknown future. If you have money, you can wait and see - practically, you have time and can use it.

This function of money is only necessary in a modern economy, which (like any other part of society) faces an unknown and indeterminate future, while knowing that it depends on present decisions. The future is therefore frightening, but can nonetheless - and, in fact, must - be acted upon. Money faces the indeterminacy of the future and allows us to manage it, offering a non-specific guarantee against our concern about tomorrow. Uncertainty can even become an opportunity. The existence of money allows the use of the openness of the future to one's advantage. As sociologists have always said, money is a social relation because it works only in reference to the society that guarantees and circulates it. It works because everyone knows that others know that it will be accepted. Seen in this way, money absorbs part of the social uncertainty: I do not know what others do, even if I know that the availability of resources depends on their behavior. However, if they spend money, I know that the circle of the economy will continue to produce money and opportunities of which I shall also take advantage. At the same time, no one knows what will happen tomorrow, but everyone knows that the others don't know either, because the future does not exist yet.

The future is radically unknowable because it depends on what we are all doing as we are trying to build it, mutually observing each other in this effort. ${ }^{2}$ This is an insight echoed by Koselleck's (1979) open future, which is uncontrollable and unpredictable because it depends on us, on our choices and on our behavior, in a reflective and self-referential situation that shows all the peculiarities and uncertainties of modern society. This unknowability, however, is also a resource: the future cannot be known because it is not yet here. But this also means that it is not yet decided; it still has to be built and we can act on it. We can imagine and design it, wait for it and be surprised by it (Shackle, 1979). Even if our expectations turn out to be false, the value of money nevertheless remains, and we can use it in different conditions 
than we had initially expected. Money allows us to act even if we cannot control the consequences, because it allows us to postpone decisions or actions, all the while retaining its value. Money can have this function only in a world of uncertainty, since it acts as a connection between the (usually wrong) plans we made in the past, our current expectations, and our expectations for a puzzling future. We can thus operate in the present to build the future, affecting the course of things and even using its openness for our purposes.

The first function of money, then, is the management of the uncertainty of the future, the use of time to increase contingency. This is what finance does and what credit has done for hundreds of years - at least since it was no longer condemned as sin and abomination, precisely because of its use of time (Le Goff, 1986). ${ }^{3}$ Credit comes into play to manage the circulation of delays and deferments, anticipations and forecasts, which are activated by money in the modern economy. Working with credit is using the future in the present. The one who borrows money commits his future by ensuring the return of a respective sum of money, but can already enjoy the wealth he or she expects to earn in the present. Tomorrow I will have to pay the installments of the loan, but today I get the money, and if I make judicious use of it, I can obtain profits that will enable me to repay the debt and gain even more money. I constrain my future today in order to build a better future, which would not have occurred if I had not acted on it in the first place. The circularity of the open future is unfolded and reveals its virtuous side. The unknowability of the future can be an opportunity.

Finance relies on this, and it multiplies and emphasizes the present use of the future with loans, securities, bonds, and the increasingly non-transparent tools of structured finance, which use elaborate models to push reflexivity to hyperbolic levels. The use of the future is itself sold and bought, and then sold again in practices like securitizations. These markets are oriented to the future (think of futures), and not simply because they try to anticipate future states in the present, in the sense of foreseeing or guessing what they will be. Derivative instruments are used to manage the difference between the present future and the future presents in the present, between what one can expect to happen tomorrow, today, and what will actually be achieved tomorrow, as a result of what one does today in order to prepare for it. In this sense, derivatives allow one to make decisions today that affect the way the future will be, while preserving the freedom to decide one way or the other when this future will be present. They produce indeterminacy while reducing it.

This extremely unlikely condition is the most abstract development of the complex management of time in the modern monetarized economy. If it is true, as Shackle maintains, that money has always been time, then derivatives sell time in the form of the management of uncertainty. They sell time in order to decide about time using time, through the difference between presents that affect each other. Because of their 'secondary' nature (they are called derivatives because they 'derive' from something else), derivatives highlight and exacerbate all the trends we have presented concerning money and the management of time. Derivatives, one could say, are the extreme implementation of economic rationality. The future is built and bound in more and more complex ways, which make more and more wealth available to operators and generate the astonishing figures circulating in the 'virtual' financial markets of our society. With the new dynamics and instruments of financial markets, a higher level of reflexivity and abstraction comes into play, which at a given point becomes autonomous and follows its own development. Although one could speculate before the 1970s, speculation now refers only to speculation and, so to speak, 'feeds' on itself. Although markets have always had their dynamics, which are led by the mutual observation of observers, this observation has now become the real object of transactions. Economic dynamics have always been for the production of the future; however, the future now depends on expectations for the future, not 
on the present data and even less on the past. This generates an intensified and progressively uncontrolled action on the future.

The open future is not a controllable future, as crises and financial breakdowns dramatically reveal. Many operators use the tools offered by financial markets to protect against possible future losses (to 'hedge' against risks), but these very operations contribute to the restlessness of markets and can also be targeted by speculators in order to bet on expectations and expectations of expectations. These operations, despite being meant to avoid risks, ultimately only contribute to the riskiness of the market as a whole. Therefore, the future is open in the sense that it cannot be determined, and remains open also when we try to bind it. The recent trend of performativity studies confirms this (MacKenzie, 2006; Callon et al., 2007; MacKenzie et al., 2007; MacKenzie, 2009). MacKenzie in particular has shown how the models developed by economics affect the very economic reality to which they refer, which changes by conforming (performativity) or deviating (counter-performativity) from the image proposed by the theory. The theory is observed as an object among others in the field of the economy, and contributes to changing economic reality as a whole. Finance is performative in the sense that it reacts to the models and expectations of actors, but it is not certain at all that it complies with them. It can do it, as was the case in the 1990s, when markets adhered by and large to the expectations set by the Black-Scholes formula (MacKenzie, 2006). ${ }^{4}$ But finance can also deviate from expectations, as in the cases of counter-performativity, in which markets contradict the predictions of the models. These are two sides of the same coin and therefore a confirmation of the openness of the future. What we do affects the future but does not determine it. The future depends on present expectations and actions, but we cannot know how.

The financial crisis of 2007/08 made this dilemma evident, revealing the naivete of attempts to 'neutralize' risk in financial markets as well as the impossibility of politically controlling the course of finance. All attempts to intervene politically into finance, from the Paulson Plan onwards, were regularly anticipated and neutralized by moral hazard and the extreme reflexivity of markets. ${ }^{5}$ This is generally true for interventions: they do not always work and may even backfire. If the markets know that they will be supported in cases of speculative excess, they can count on this and produce their form of moral hazard, increasing the risks and reducing caution and controls. Protection against risk can thus produce new risks because one behaves differently than one would have done otherwise.

Interventions, both of a financial and political nature, certainly have effects, but hardly those that are desired, because the actors who execute them are not external agents, but are instead embedded in the market on which they act. Prediction and intervention, therefore, themselves produce effects that they can neither control nor take into account. This is an inevitable consequence of the openness of the future, which the crisis of 2007/8 has shown yet again and which we have to face continuously. But even though we know this, we nevertheless must make decisions, particularly if we work in finance or politics. How can we account for this circularity and for the related (radical) uncertainty? Can we simply go on operating, and if so, how?

In recent years, support has grown for the idea that we should give up on the illusion of regulation because financial markets are no longer organized in a hierarchical way, with a vertex (Central Bank) that controls operations all the way out to the periphery of the system. Decisions and information are now distributed to a variety of operators, official and unofficial, which are regulated as well as 'over the counter'. Even private individuals operate directly on markets, giving rise to a sort of diffused and non-transparent 'heterarchy', with flows going in several different directions at the same time. The (external) interventions of politics and/or law 
add further elements of complexity and 'irritation', which cause their own feedback effects, and these can very well disturb rather than steer the market's internal processes. This does not mean that financial markets should remain free from intervention. Markets need external constraints in order to be able to build expectations. They need to be monitored in order to be able to grow in a controlled manner. But perhaps it would be advisable to avoid aiming at specific effects, instead acknowledging the reactivity of the markets, and trying to use this while remaining ready to learn from their unpredictable behavior. Are there examples of this kind of attitude? As I already mentioned, it seems to me that the policies of QE can be read in this way, helping us to understand the reasons behind their relative success - and failure.

\section{Steering economies from the inside}

QE is an unconventional monetary policy that has the interesting feature of being effective but inexplicable. As Fed chairman Ben Bernanke put it, "The problem with QE is it works in practice, but it doesn't work in theory". ${ }^{6}$ Accordingly, theory must change to take this into account, and such a change requires first of all more attention to our topic, the temporalities of finance. The way QE actually operates is based on time, as it tries to react to the attitude prevalent in the post-crisis markets, which is the opposite of the one that characterized the previous expansive phase. Instead of intensively using the future in the present, there was (and still is) a general unwillingness to use the future and therefore also to shape it after the crisis. That is why deflation, a constant concern in recent years, is a problem. Instead of investing and borrowing (that is, instead of working on the future), people save, counting on falling prices. But then consumption decreases and companies do not make profits, invest less, and prices fall further down. We do not build the future and therefore the economy stagnates.

QE tries to intervene in this vicious circle, inserting (or 'injecting') liquidity into the economy to boost investment. In our terms, it tries to stimulate the use of time by creating money, which is the economic equivalent of the availability of the future. In this way, it brings the future into markets, hoping that it will be used. QE is basically the creation of money, even if money is not printed but produced by electronic means and inserted indirectly into the economy. Central Banks that implement QE measures do not act directly on the economy as external operators regulating the behavior of agents. The intervention is heavy (it has been called a 'monetary bazooka'), but it is not crude. It presupposes a certain awareness of performativity, because Central Banks actually act as one investor among many within their own economy. Central Banks use their privileged position to do what others cannot do (i.e., create money), but they do not impose an outcome from outside the markets. They rather create incentives and opportunities from within, leaving markets the freedom to react and to use them as they see fit. This is part of the theoretical inexplicability of QE. We know that the bazooka has effects, but no one knows what they will be - because the agent triggering them (the Central Bank) operates as an agent among others in the complex financial environment of which it is also part and which it cannot determine.

The Central Bank buys financial assets (shares or securities, even toxic ones) from banks, causing a rise in demand and, consequently, an increase in price. Since interest rates do not change, a price increase should lead to a reduction in yields. In the case of government securities, yields are linked to the interest rate, which should drop too, also affecting the performance of other obligations. Access to credit should become less expensive, so families and businesses should have more money available because of the additionally created money, 
and because they can also borrow it more easily. This way consumption and investment should be boosted, thereby boosting the use and shaping of the future in the process.

Yet this whole construction is hypothetical, because it relies on assumptions about market reactions and is full of contingencies. Banks, for example, could decide not to use liquidity to grant loans but instead to deposit it in the Central Bank itself, improving their margins and avoiding risks - i.e., narrowing instead of expanding future possibilities. Investors could gain confidence and start to commit more funds, but they could also interpret QE itself as an index of the severity of the situation, shrinking their outlays even more. These uncertainties represent the other side of the recognition of performativity: it is up to the future to decide what to make of the incentives offered, which will have effects in any case. The differences in outcome will depend on the context and the specific circumstances, including what we are here calling the temporalities of finance.

In the US, these measures have apparently worked. The Federal Reserve's QE policy, along with government efforts that led to an increase in the federal deficit from $2.8 \%$ in 2007 to $12 \%$ in 2009 , seem to have led the country out of the crisis, with job growth, increased GDP, moderate inflation, and a controlled decline of the value of money. In other words, the construction of the future has been set in motion. Based on the US experience, what can we expect from the adoption of the same policies in the Euro area? Since it is an indirect action (its effectiveness, in fact, depends on it), it makes no sense to expect a precise result, and even less sense to expect an identical result. Instead of a controlling action that aims at a predetermined outcome, it presents an attempt to stimulate the autonomous dynamics of the economy from the inside. And the economy in the Eurozone is different from the US economy.

The way in which US culture and society conceive of their relationship with time and in particular with the future - precisely the US temporality that this special issue sets out to investigate - also influences the effects of QE in the US. Even if we do not know in detail how this temporality works, we know very well that it is different from the European one, in finance and elsewhere. You only need to take a subway ride in New York City to notice the difference: the walls are plastered with advertisements for private and public schools, investment proposals, and generally with calls for preparing in the present for the future, thus making manifest America's specific cultural bet on the future. The educational field is only the clearest example.

Europe has a long and consistent tradition in academic education, which can seem to be characterized by a kind of fatalism, at least from an American point of view. The European tradition relies on the assumption that the institutions will continue to be available, and it entrusts to the present, as it is actualized, the choice of careers and of opportunities. Ideally, children choose which school and college they want to attend, once their course of study has led them to develop and understand their own interests. In Europe, you tend to go from the present to the future. The setting of the future (in this as in other fields) is the result of the past and the path that led to the present. The possibilities envisaged depend on this path.

In the US the attitude is different, not because of what some call a lack of historical sense (which is not true), but because of a different way of dealing with history, or rather because of a different way of setting the relationship of the past with the openness of the future. What appears as a kind of obsession with the construction of careers from a European perspective, can indeed be interpreted as a reversal of temporal priorities, or the attribution of meaning to the present from the opposite direction. In the US, you go from the future to the present. The sense of the present is the result of a projection of the future, on which the interpretation and evaluation of the past depends. The sense of the present is 'colonized' by the construction of the future: decisions in the present depend on the future that one wants to 
build, and the available possibilities will be defined accordingly. From this perspective, it appears normal to 'sacrifice' the present to the promise of a future that does not yet exist (using credit to be able to build it, or saving for years in order to pay tuition), because without reference to the future, the present itself does not seem to make much sense.

It is difficult to say which of the two attitudes is more compatible with the openness of the future. But they are different attitudes that also become manifest in the temporality of finance; for example, in the way access to credit is understood and used. In the US, access to credit is much easier and requirements are more relaxed, both in the public and the private sector. Households and businesses are comparatively more indebted, confirming a greater propensity to commit the present to the construction of the future. But this difference also pertains to the way one makes debts: big US companies are financed primarily (about 80\%) on the financial market, while the mostly small or medium-sized European companies get credit from banks, exposing themselves directly to finance only by $10-20 \%$.

Finance, as we have seen, can be described as a large apparatus for the use of the future in the present - or, to put it differently, for the present intervention in the construction and structuring of the future. In the US it is certainly more common, and people seem to have become accustomed to taking on bigger loans. In Europe, people are more reluctant to do this and prefer a less aggressive approach to the future, with less recourse to speculation and greater mediation by banks. One gives up potential gains, but one also gains the sense of a less constrained future. One gives up the space of mobility offered by a (possibly) greater future wealth, but one keeps the availability of unbound possibilities. In both cases, you obviously take risks, but from the European perspective, the risks seem less risky. As a European, you do not attribute the risk to your own decision.

The point here is not to ask which is the better attitude (a meaningless question), but rather, to ask if and how these different cultural approaches affect time-oriented interventions like QE policy. If Europeans are more inclined to see the future as the result of the present (rather than the present as a preparation of the future), it would be advisable to act on present fears and hopes, i.e., to work on expectations. The willingness to build the future would be a consequence. Actually, in the early European debates on this issue, commentators recommended a series of criteria to support the success of a European QE program that all went in this direction (see Monacelli, 2011). The program was supposed to be announced publicly, with a clear amount and a fixed duration, in order to strengthen its credibility and to guide expectations. The program was also supposed to be as broad as possible, to reassure markets permanently on the default risk of sovereign countries, and was to address the whole Euro area in order to safeguard ex-post flexibility (which allows policymakers and central bankers to refocus if the crisis moves to different countries). If this worked, the argument went, the actual budget commitment would probably be smaller - if you announce the willingness to spend, you often need to spend less. You act on the possible to orient the real. In Koselleck's terms, you act on the present future to orient the future present (or presents).

The intervention announced by the European Central Bank's (ECB) Governor Mario Draghi on January 22, 2015, fulfilled these requirements. The ECB declared that it would buy public and private debt securities (official announcement) from March 2015 until at least September 2016 (duration fixed in advance), at the rate of 60 billion Euros per month (specific amount), and in any case until the inflation rate in the Eurozone returned to somewhere near the preferred level of $2 \%$. Obviously, this did not give any guarantee on the success of the European QE policy, but it implicitly signaled a heightened awareness of the temporality of finance compared to earlier forms of public intervention, which were oriented towards planning and controlling the future, rather than to an indirect intervention of a performative kind. This 
was not an attempt to direct the course of things, but rather to stimulate it, in order to see how the future will react - "a mix of commitment and flexibility", as some have described it (Monacelli, 2011: n.p.). This does not only take into account the temporality of finance, but apparently also considers temporalities in the plural - the different temporal attitudes at play in different contexts (US and Europe), which affect the way one sees the present and prepares for the future, before and beyond forecasts and schedules.

There was no guarantee of success, as with any action on the open future. You cannot know in advance if the intervention will be successful. You may know, however, that no one can know it, and that this also applies to any alternative intervention. In such a situation, it makes little sense to ask the question of success. It rather makes sense to ask if and how the intervention on the future implies the ability to learn, through a constant re-modulation of the relationship between present future and future present. This implies an ability to observe finance considering the forms of its temporality. Indeed, after a few months, the comments of observers on the ECB's QE policy reflected the openness of the measure and showed a corresponding openness. Nobody responded univocally with a 'yes' or a 'no'. Commentators considered the multi-dimensional character of the situation and in general tended to make judgments that referred to future developments. With the future being open, the judgments were correspondingly open.

Even those who tended to deny the success of the measure made their judgment on the future contingent on "what one can legitimately expect" (Monacelli, 2015a: n.p.). Success is measured not directly in accordance with the desired effects (i.e., the rise of inflation), but rather in reference to indirect effects, such as the performance of the euro exchange rate against the dollar, and especially the return of confidence amongst economic agents (as in Di Colli, 2015, for example). 2015 was the first year in which the periodical growth forecast went upwards instead of downwards. The ECB itself apparently followed a policy of ongoing learning, modulating its further action depending on the outcome of the measures already taken. The announcement of the extension of the program to March 2017 was made at the end of 2015, showing flexibility in the deadlines. But most importantly, the ECB raised the fee that banks pay to hold reserves at the ECB itself, reacting to the (dreaded) tendency of banks to 'park' the money obtained through QE, and pushing them to use it instead for loans to businesses and consumers. The ECB learned from the behavior of banks, which were the result of its measures, and acted accordingly.

The effects of QE in Europe were still very different from those in the US, and their temporalities are just as different. European countries tend to adopt a restrictive fiscal policy to pursue a balanced budget (Baglioni, 2015). In this way they continue to bind the production of the future to a 'settling of accounts' with the past. Monacelli (2015b) proposes the image of an escalator whose speed depends on the passengers making steps forward or moving backward. European operators apparently wait to move forward until the speed of the escalator increases, while the speed of the escalator won't increase until the passengers start moving. The construction of the future is not the driving force of the present but its consequence. As Keynes taught, in Europe as in the US, the reference to time is the basis of the functioning of the economy. 


\section{Notes}

1. In the Grundrisse, for example, he states: "Economy of time, to this all economy ultimately reduces itself" (Marx, 1973/1939: 172).

2. It is at this level, at the level of second-order observation, that needs are generated, which remain always inexhaustible because they address the indeterminacy of the future. The world (or object of first-order observation) has little to do with it, because it is only present and, hence, inevitably inadequate with respect to future needs. Observing the availability of goods doesn't help us to know what is perceived as scarce (because others also want to appropriate it), or which time horizon is activated (i.e., which future one refers to). We must observe observers, and observe them in time.

3. The creditor gets a profit by lending his money, without producing or providing anything other than the time elapsing until the money is returned. The creditor in practice sells time. The critique was that time belongs to God, who freely gave it to man so that he might use it, not to sell it for a profit.

4. The crucial thing to remember here is that the Black-Scholes formula refers to a model of financial markets which, although it did not correspond to the reality of finance at the time when it was first introduced, has become increasingly accurate as the formula has been used to guide operations. In other words, reality adapted to the theory.

5. The so-called Paulson Plan was signed into law in October 2008 by President George W. Bush as the Emergency Economic Stabilization Act of 2008.

6. Bernanke made this remark in a question and answer session at the Brooking Institution in Washington DC (quoted in Harding, 2014: n.p.).

\section{References}

Baglioni, A. (2015) Perchè la Bce sceglie ancora il Quantitative easing. Lavoce.info [Online], 13 November. Available at: <http://www.lavoce.info/archives/38316/perche-la-bce-sceglie-ancora-ilquantitative-easing/>. Accessed 30 January 2018.

Callon, M., Millo, Y. and Muniesa F. (eds.) (2007) Market Devices. Oxford: Blackwell.

Di Colli, S. (2015) Con il Qe torna la fiducia. Lavoce.info [Online], 15 May. Available at:

<http://www.lavoce.info/archives/34733/con-il-qe-torna-la-fiducia/>. Accessed 30 January 2018.

Esposito, E. (2013) The structures of uncertainty: Performativity and unpredictability in economic operations. Economy and Society, 42(1): 102-29.

Keynes, J.M. (1936) The General Theory of Employment, Interest and Money. London: Macmillan. Koselleck, R. (1979) Vergangene Zukunft: Zur Semantik geschichtlicher Zeiten. Frankfurt a.M.: Suhrkamp.

Harding, R. (2014) US quantitative measures worked in defiance of theory. Financial Times, 13 October. Available at: <https://www.ft.com/content/3b164d2e-4f03-11e4-9c88-00144feab7de>. Accessed 29 May 2018.

Ingham, G. (2004) The Nature of Money. Cambridge: Polity Press.

Le Goff, J. (1986) La bourse et la vie: Economie et religion au Moyen Age. Paris: Hachette.

MacKenzie, D. (2006) An Engine, Not a Camera: How Financial Models Shape Markets. Cambridge, MA: MIT Press.

MacKenzie, D. (2009) Material Markets: How Economic Agents Are Constructed. Oxford: Oxford University Press.

MacKenzie, D., Muniesa, F. and Siu, L. (eds.) (2007) Do Economists Make Markets? On the Performativity of Markets. Princeton, NJ: Princeton University Press. 
Marx, K. (1973/1939) Grundrisse: Foundations of the Critique of Political Economy, translated by M. Nicolaus. New York, NY: Random House.

Monacelli, T. (2011) Una ricetta per l'Europa: il Quantitative Easing. Lavoce.info [Online], 8 August. Available at: <http://www.lavoce.info/archives/27098/una-ricetta-per-leuropa-il-quantitativeeasing/>. Accessed 30 January 2018.

Monacelli, T. (2015a) Qe e inflazione: poche illusioni. Lavoce.info [Online], 3 November. Available at: <http://www.lavoce.info/archives/38149/qe-e-inflazione-poche-illusioni/>. Accessed 30 January 2018.

Monacelli, T. (2015b) Una politica monetaria timida per una grande stagnazione. Lavoce.info [Online], 4 December. Available at: <http://www.lavoce.info/archives/38763/una-politica-monetaria-timidaper-una-grande-stagnazione/>. Accessed 30 January 2018.

Shackle, G.L.S. (1972) Epistemic and Economics: A Critique of Economic Doctrines. Cambridge: Cambridge University Press.

Shackle, G.L.S. (1979) Imagination and the Nature of Choice. Edinburgh: Edinburgh University Press. Shackle, G.L.S. (1990) Time, Expectations and Uncertainty in Economics. Aldershot: Edward Elgar. Sohn-Rethel, A. (1990) Das Geld, die bare Münze des Apriori. Berlin: Wagenbach. 